УДК 007

\title{
МОДЕЛИ ИНФОРМАЦИОННЫХ ПОТОКОВ НА МУНИЦИПАЛЬНОМ УРОВНЕ
}

\author{
Данилина Елена Ивановна \\ доктор экономических наук, профессор \\ Институт образовательных технологий \\ и гуманитарных наук
}

\begin{abstract}
Аннотация: В статье показана значимость информации, особенности модели протекания информационных потоков в целевом управлении на местном уровне, указаны особенности информационного потока «власть население». Представлено ранжирование цели муниципального управления. По результатам исследования обоснована необходимость оценки характера информационных потоков.

Ключевые слова: Информация, информационные потоки, модели, модели протекания информационных потоков в целевом управлении, условия реализации муниципальных программ и проектов.
\end{abstract}

\section{MODELS OF INFORMATION FLOWS AT THE MUNICIPAL LEVEL}

\section{Danilina Elena Ivanovna}

\begin{abstract}
The article shows the importance of information, the features of the information flow model in target management at the local level, the features of the information flow "power - population" are indicated. The ranking of the purpose of municipal administration is presented. Based on the results of the study, the need to assess the nature of information flows is justified.

Key words: Information, information flows, models, models of the flow of information flows in target management, conditions for the implementation of municipal programs and projects.
\end{abstract}




\section{ВСЕРОССИЙСКИЕ НАУЧНЫЕ ЧТЕНИЯ \\ ИМЕНИ АКАДЕМИКА А.Д. САХАРОВА}

В настоящее время значимость информации, в том числе организация информационных потоков, в наибольшей степени проявляется в управлении на муниципальном уровне. Представляет интерес модель протекания информационных потоков в целевом управлении на местном уровне, разработанная В.А. Никитовым, в которой выделена серия информационных потоков, в том числе, когда информация о проблемах, потребностях, заданиях и т.п. поступает в орган местного самоуправления от населения, научной общественности, организаций и учреждений муниципалитета и из вышестоящих органов власти; когда поступившая информация в дополнении с внутренними потоками органов местного самоуправления лежит в основе формулировки целей муниципального развития; сформулированные цели муниципального развития отражается в муниципальных целевых программах и стратегическом плане, информация о которых доводится до населения и организаций и учреждений (информирование общественности является условиям участие в достижении целей), далее следуют действия по достижению цели; информация о результатах доводится до органа местного самоуправления, населения, научной общественности, организаций и учреждений, цикл целевого управления начинается заново [6].

Таким образом, одним из ключевых в данной модели является информационный поток «власть - население», значение и роль которого в реализации целевого управления на муниципальном уровне нередко недооценивается, а вместе с тем, целевое управление на местном уровне без указанного информационного потока теряет свой смысл. Понимание намерений власти и их поддержка населением - условие реализации муниципальных программ и проектов [3].

Поэтому при анализе роли информационных потоков в целевом управлении основное внимание необходимо уделять именно информационному потоку «власть - население», связывающему между собой органы местного самоуправления и населения муниципального образования (как в направлении власть - население, так и в обратном направлении), который B.А. Никитов назывет «общественным» информационным потоком [6].

Представленная модель протекания информационных потоков в целевом управлении на местном уровне в зависимости от того, носят ли информационные потоки характер состоявшихся либо несостоявшихся коммуникаций, имеет следующие варианты ее реализации: 
1. Информационные потоки между органами власти и населением как в прямом, так и в обратном направлениях содержат полную и достоверную информацию, которая с одной стороны учитывается органами власти при формулировке цели муниципального развития, тем самым достигается согласование целей объекта и субъекта управления, а с другой стороны убеждает население в заинтересованности властей в решении актуальных для жителей муниципального образования проблем; данное обстоятельство обеспечивает процесс достижения цели дополнительным ресурсом поддержкой со стороны населения;

2. Информационный поток от населения к органам власти содержит полную и достоверную информацию, которая, однако, не доходит либо не учитывается органами власти при формулировке цели муниципального развития, то есть имеет место лишь видимость сбора информации; информационный поток в обратном направлении содержит полную и достоверную информацию - в этом случае отсутствие достоверной информации восполняется вымышленной информацией о состоянии объекта управления, это происходит из-за того, что согласно принципам системного подхода система не может существовать без информации. В итоге сформулированная цель муниципального развития может существенно отличаться от целей населения муниципального образования, что вполне естественно будет восприниматься как угроза и вызовет противодействие достижению цели;

3. Информационный поток от населения к органам власти вообще отсутствует; информационный поток в обратном направлении содержит полную и достоверную информацию - результат целевого управления в этом случае аналогичен предыдущему;

4. Информационный поток от населения к органам власти содержит полную и достоверную информацию, которая учитывается органами власти при формулировке целей муниципального развития, информационный поток в обратном направлении хотя и содержит соответствующую информацию, но не достигает конечной цели, то есть имеет место формальный подход к информированию населения «для галочки». В этом случае, несмотря на то, что сформулированные цели являются результатам согласования целей объекта и субъекта управления, может иметь место ситуация, когда населения, не зная об этом, будет активно сопротивляться действиям властей, 


\section{ВСЕРОССИЙСКИЕ НАУЧНЫЕ ЧТЕНИЯ \\ ИМЕНИ АКАДЕМИКА А.Д. САХАРОВА}

и вместо ресурса поддержки система целевого муниципального управления получит ресурс разрушения;

5. Информационный поток от населения к органам власти содержит полную и достоверную информацию, которая учитывается органами власти при формулировке целей муниципального развития, информационный поток в обратном направлении отсутствует - результат целевого управления в этом случае аналогичен предыдущему. Остальные варианты, когда информационные потоки между органами власти и населением отсутствуют либо носят характер несостоявшихся коммуникаций, свидетельствуют о разрушении системы муниципального целевого управления.

В региональном целевом управлении входящий информационный поток (от населения к органам власти) имеет своей конечной задачей учет целей населения при формулировке целей муниципального развития. Поэтому можно сказать, что эффективность данного потока информации можно оценить исходя из степени согласованности целей, заявляемых местными органами власти в программах и стратегии социально-экономического развития, и целей, актуальных для населения муниципального образования. Если цели согласованы, то это может свидетельствовать об эффективности информационного потока. Для этого необходимо, прежде всего, проранжировать цели муниципального управления, помочь в этом может, предложенная С. В. Малышем, 5-балльная шкала оценки успешности целеполагания [ 5]:

0 - заинтересованность проблемой отсутствует, ничего не предпринимается для ее решения - эта ситуация проявляется в том случае, если та или иная проблема воспринимается населением как актуальная, но она не лежит в основе целеполагания ни одной муниципальной целевой программы или стратегического плана развития территории, не осуществляется информирования населения о данной проблеме.

1. признается существование проблемы, отсутствие достаточной заинтересованности в принятии конструктивных мер по ее решению - эта ситуация проявляется в том случае, если та или иная проблема воспринимается населением как актуальная, но она также не лежит в основе целеполагания ни одной муниципальной целевой программы или стратегического плана развития территории, однако в местной прессе осуществляется информирования населения о данной проблеме. 
2. отдельные попытки решения проблемы - ситуация, когда действия по решению актуальных проблем муниципалитета заложены в качестве отдельных задач или подцелей в рамках муниципальных целевых программ.

3. важность проблемы признается, руководство проявляет активность в еe решении - ситуация, когда та или иная проблема, воспринимаемая населением как актуальная, лежит в основе формулировки целей муниципальных целевых программ или отдельных направлений стратегического плана развития территории.

4. высшая степень признания актуальности проблемы - ситуация, когда та или иная проблема, воспринимаемая населением как актуальная, лежит в основе не только формулировки целей муниципальных целевых программ, но и целей и подцелей стратегического плана развития территории. Далее рейтинг целей муниципального управления сопоставляется с перечнем целей, актуальных для населения.

Изучение исходящих информационных потоков (от органов власти) при реализации целевого управления на местном уровне в виду зависимости социальных систем от субъективизма людей связано с исследованием доверия населения к принимаемым властью решениям [2]. Степень доверия можно оценить не только прямо, но и косвенно, оценивая желание или нежелание граждан обращаться в органы власти для решения своих проблем (исследованиями установлена прямая связь между удовлетворенностью результатами обращения и степенью доверия [3]. Кроме того, установлено, что и доверие, и удовлетворенность во многом зависят от того, как опыт взаимодействия с органами власти влияет на восприятие гражданами степени собственной информированности, возможности личного контроля, а также влияния на процессы, связанные с деятельностью институтов власти.

Таким образом оценить эффективность исходящих информационных потоков (от органов власти) можно посредством изучения восприятия гражданами степени собственной информированности, удовлетворенности результатами обращения в органы местного самоуправления. Оценка информированности населения позволяет не только оценить эффективность информационного потока от органов местной власти к населению, но и позволяет проанализировать активность участия населения в процессе целевого управлении. В основе этого тезиса лежат выводы, полученные А.В. Жаворонковым в своих работах. И, прежде всего, вывод о том, что связь 
социальной активности (а участие населения в разработке и реализации муниципальных целевых программ и планов стратегического развития территории является одной из форм проявления социальной активности) и информированности представляет собой целостный мотивационнодеятельностный тип. Высокой активности соответствует максимально возможная информированность и наоборот - низкой активности соответствует предельно малая информированность [4].

А.В. Жаворонков доказал, что «чем больше включенность человека в социальное действие, тем выше знания о нем, тем больше поддержка положительных моментов этого действия и наоборот» [3]. Соответственно, можно сделать вывод, что в основе эффективности целевого управления лежат эффективные информационные потоки «власть - население». Далее А.В. Жаворонков доказал, что «высокой степени осознания своих объективных информационных потребностей (выраженных в реальном приеме социальной символики) соответствует высокоактивное поведение в сфере информационного приема. И наоборот» [4].

Иными словами при изучении роли информационных потоков «власть население» в целевом управлении на муниципальном уровне будем исходить из положения, что чем более информировано население, тем более оно активно. Чем меньше оно знает, тем длиннее лаг проверки неадекватно принятых управленческих решений, но тем больше непредсказуемость поведения населения, темп возрастания энтропии в системе человеческой активности и вероятность непредсказуемости форм социальной катастрофы.

Тем самым можно сделать вывод, что успешная работа администраций всех уровней, развитие местного управления во многом зависят от эффективности их информационного взаимодействия с населением. Показателями такого взаимодействия являются уровень информированности людей о важнейших программах и направлениях деятельности городских властей, интенсивность использования для этой цели многообразных источников информации и оценка населением работы администрации по информированию горожан. Разработка инструментария оценки эффективности целевого управления развитием муниципальных образований с включением в него социальной составляющей позволит более объективно оценивать степень влияния управленческих решений местных органов власти на повышение качества жизни населения. Исследование социальной 
эффективности управления предполагает максимально возможный учет мнения жителей муниципального образования, что позволяет дополнить количественную оценку управления (по результатам) оценкой его качества (соответствия целей, поставленных местными властями, ожиданиям населения). Это будет способствовать постановке обоснованных целей и задач и принятию адекватных им управленческих решений при разработке и реализации стратегии и программ социально-экономического развития муниципальных образований.

Для успешной реализации принципов целевого управления на местах необходима рациональная организация информационных потоков как в направлении от органов местного самоуправления к населению, так и в обратном направлении. Для того чтобы определить, какой из названных вариантов реализации модели имеет место в действительности, необходимо оценить характер информационных потоков и установить являются ли они состоявшимися коммуникациями либо нет.

\section{Список литературы}

1. Гилязутдинова И.В., Киселев С.В., Файзрахманов М.Д. Взаимодействие государственных и предпринимательских структур как условие инновационного развития производственной инфраструктуры в сфере услуг // Вестник Казан. технол. ун-та. 2015. №4. С. 340-346.

2. Гимазова Ю. В. Государственное и муниципальное управление. учебник / Ю.В. Гимазова. - М.: Юрайт, 2017. - 464 с.

3. Жаворонков А.В. Концептуальные основания измерения соц. Активности в рос. обществе: автореф. дисс.доктора социол. наук. М. 2009. 45 с.

4. Жаворонков А.В. Об устойчивости распределения населения по параметрам информированности, активности и уровню семиотической подготовки // Социологические исследования. 2010. № 5. С. 110- 113.

5. Малыш С.В. Целеполагание в социальном управлении организационными процессами: автореф. дисс. ... канд. социол. наук. М., 2010. 20 с.

6. Никитов В.А. Информационное обеспечение муниципального управления. М.: КноРус. - 2017. - 266 с.

() Е.И. Данилина, 2021 